УАK 347.965

ББК 67.75

DOI 10.22394/1682-2358-2019-1-39-46

P.A. Zelensky, Candidate of Sciences (Law), Docent of the Theory of Law Department, Povolzhsky Institute of Management named after P.A. Stolypin, Branch of the Russian Presidential Academy of National Economy and Public Administration

\section{DEVELOPMENT \\ OF FREE LEGAL \\ AID SYSTEM \\ IN RUSSIA: \\ CHALLENGES AND PROSPECTS}

Features of legal regulation of the system of free legal aid in Russia are analyzed. The experience of providing free legal aid by both state and non-state actors is considered. The necessity of the increased attention of authorities, legal community and other subjects to the problems of free legal aid availability for the population and the quality of its provision is substantiated.

Key words and word-combinations: free legal aid, advocacy, state legal bureaus, legal clinics.
П.А. Зеленский, кандидат юридиеских наук, дочент кафедрь теории права Поволжского института упраһления имени П.А. Стольпина - филиала Российской академии народного хозяйства и государственной службы при Президенme РФ (email: selenskii_pavel@mail.ru)

\section{РАЗВИТИЕ СИСТЕМЫ БЕСП ААТНОЙ ЮРИАИЧЕСКОЙ ПОМОЩИ

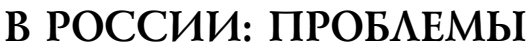 И ПЕРСПЕКТИВЫ}

Аннотация. Анализируются особенности правового регулирования системы бесплатной юридической помощи в России. Рассматривается опыт оказания бесплатной юридической помощи как государственными, так и негосударственными субъектами. Обосновывается необходимость повышенного внимания органов власти, юридического сообщества, иных субъектов к проблемам доступности бесплатной юридической помощи для населения и качества ее оказания.

Ключевые слова и словосочетания: бесплатная юридическая помощь, адвокатура, государственные юридические бюро, юридические клиники.

B

современной России достаточно остро стоят проблемы правового просвешения, связанные с повышением уровня правовой культуры населения. Значительная часть российских граждан имеет довольно смутные представления о содержании отечественного законодательства, принадлежащих им субъективных правах и способах их за- 
щиты, имеющихся обязанностях. Насемение, как правило, испытывает потребность в получении оперативной квалифицированной юридической помощи. В случае невозможности ее правоприменения в тех или иных жизненных ситуациях последствия могут быть достаточно серьезными, порой сравнимыми с затягиванием обрашения к врачу при опасной болезни.

Получение квалифиџированной юридической помощи нередко связано с Аостаточно высокой стоимостью данных услуг, что делает затруднительным, а порой и невозможным дмя многих граждан обращение за такой помощью. По официальным данным, в России сегодня свыше 20 млн человек имеют АохоА ниже прожиточного минимума и находятся фактически за чертой бе Аности [1]. Если применить «метоА мишений», использованный Росстатом в экспериментальном порядке, то уровень бедности в России составляет порядка 24,8-25,2\% (около 36 млн человек). [2]. В сложившейся обстановке множество Аюдей остро нуждаются в квалифиџированной бесплатной юриАической помощи.

Ао недавнего времени, в условиях отсутствия спещиального федерального закона о беспматной юридической помощи (БЮП), порядок предоставления бесплатной юридической помощи устанавливался ст. 26 Федерального закона от 31 мая 2002 г. № 63-Ф3 «Об адвокатской деятельности и адвокатуре в Российской Федерации» [3]. Аанная норма касалась исключительно адвокатского сообщества и применялась в гражданском судопроизводстве, а также при оказании консультаџионной правовой помощи, составлении правовых документов. В угомовном судопроизводстве таким законом был и продолжкает оставаться сегодня Уголовно-процессуальный кодекс Российской Федерации.

Важным этапом в развитии системы бесплатной юридической помощи в России стало принятие Федерального закона от 21 ноября 2011 г. № 324-Ф3 «О бесплатной юридической помощи в Российской Федераџии» (Аалее - Закон № 324-Ф3). Аанным Законом устанавливаются конкретные категории миџ, имеющих право на бесплатную юридическую помощь, конкретные случаи ее оказания, а также определяется круг субъектов, полномочных на оказание БЮП, и требования к ним. Всех субъектов, оказывающих БЮП, Аанный Федеральный закон подразделим на две категории - участников государственной системы оказания бесплатной юридической помощи [4, с. 69-70] и участников негосударственной системы оказания БЮП.

К участникам государственной системы оказания БЮП относятся федераАьные органы исполнительной власти и подведомственные им учреждения; органы исполнительной власти субъектов РФ и подведомственные им учреждения; органы управления государственных внебюджетных фондов; государственные юридические бюро. Право участия в государственной системе оказания БЮП принадмежит цемому ряду домжностных миџ: адвокатам, нотариусам и другим субъектам правоотношений в установленном законом порядке. К участникам негосударственной системы оказания БЮП относятся юридические кАиники (студенческие консультативные бюро, студенческие юридические бюро и т.А.) и негосударственные центры бесплатной юридической помощи. 
Из приведенного перечня участников государственной и негосударственной систем оказания БЮП более поАробно рассмотрим несколько субъектов, оказывающих всестороннюю, комплексную правовую помощь по широкому кругу вопросов. Федеральные органы исполнительной власти и подведомственные им учреждения, органы исполнительной власти субъектов РФ и подвеАомственные им учреждения, органы управления государственных внебюАжетных фондов оказывают бесплатную правовую помощь кишь по узкому кругу вопросов, относящихся к компетенции соответствующих органов и, соответственно, не входят в предмет данного исследования. Адвокаты, государственные юридические бюро, юридические кАиники и негосударственные центры бесплатной юридической помощи занимаются оказанием БЮП без привязки к какой-либо определенной сфере, по самым различным вопросам, ограничиваясь в то же время рамками, установленными рассматриваемым Федеральным законом.

Насколько эффективна деятельность данных субъектов по оказанию БЮП, с какими проблемами организации этой деятемьности они сталкиваются? Какое развитие получили новые Амя России субъекты оказания бесплатной юриАической помощи?

В соответствии с региональным законодательством о бесплатной юридической помощи основными участниками государственной системы оказания БЮП в большинстве субъектов РФ явмяются адвокаты. В некоторых российских регионах (Тамбовская область, Архангельская область, Пензенская область, Карачаево-Черкесская Республика, Чеченская Республика, и др.) в качестве основного участника государственной системы оказания правовой помощи действуют государственные юридические бюро. В Аругих регионах (Томская область, Иркутская обцасть, Ямало-Ненеџкий автономный округ, Свердловская область, Волгоградская область, и Ар.) государственные юридические бюро и адвокаты явмяются участниками государственной системы оказания бесплатной юридической помощи совместно [5, с. 61] .

Адвокатское сообщество - правозащитный институт с достаточно богатой историей и традициями оказания правовой помощи, в том числе и бесплатной. Бесплатная правовая помощь оказывалась адвокатами и до принятия Закона № 324-Ф3 - в рамках исполнения положений ст. 26 Федерального закона от 31 мая 2002 г. № 63-Ф3 «Об адвокатской деятемьности и адвокатуре в Российской Федерации».

В отличие от адвокатуры государственные юридические бюро - сравнительно «молодой» институт. Незадолго Ао принятия Закона № 324-ФЗ было принято постановление Правительства РФ от 22 августа 2005 г. № 534 «О проведении эксперимента по созданию государственной системы оказания бесплатной юридической помощи малоимущим гражданам» [6], в соответствии с которым в десяти субъектах Российской Федерации были созданы государственные юридические бюро. В дальнейшем число регионов, в которых созданы и действуют государственные юридические бюро, увеличилось до 25. С принятием Закона № 324-ФЗ государственные юридические бюро, наряду с иными участниками государственной системы БЮП, оказывают 
бесплатную юридическую помощь уже в порядке, определенном данным законом.

В результате обобщения опыта оказания бесплатной правовой помощи субъектами государственной системы БЮП в различных регионах, были выявлены недостатки организаџии сложившейся системы. К числу важнейших из них относится неэффективность при освоении бюАжетных среАств, выдеменных на оказание БЮП. Так, в бюджете Саратовской области на 2013 г. было предусмотрено 8755,8 тыс. рублей на оплату труда субъектов государственной системы БЮП в рамках реализации Закона № 324-ФЗ. ОАнако кассовые расходы составили всего мишь 174, 6 тыс. рублей. В обшей сложности в 2013 г. бесплатную помошь от адвокатов получил мишь 71 житель области. В 2014 г. сложилась аналогичная ситуаџия [7]. Похожее положение наблюАается во многих Аругих российских регионах. Так, в 2013 г. в Чувашской Республике из 12255 тыс. рублей, выделенных на оказание БЮП, адвокаты использовали цишь 1396 тыс. рублей, то есть 11,17\% [8]. В посмедние годы статистика освоения выдеменных на оказание БЮП бюАжетных среАств несколько улучшилась, но незначительно - в основном за счет уменьшения размеров запланированных на эти џели средств в соответствующих региональных бюджетах.

В чем же причина столь низкого уровня освоения бюджетных средств, выдемяемых регионами на оказание бесплатной правовой помощи? Согласно информации Адвокатской палаты Саратовской области в процессе оказания БЮП выявлены многочисленные случаи, когда адвокаты не имели возможности оказать юридическую помощь мьготным категориям граждан в связи с ограниченным перечнем вопросов, предусмотренных ч. 2, 3 ст. 20 Закона № 324-ФЗ. В частности, гражАане, относящиеся к категориям, установленным ч. 1 ст. 20 указанного Закона, нередко нуждались в преАставлении их интересов в судах при установлении фактов, имеющих юридическое значение; в случаях защиты прав потребителей в части предоставления не только коммунальных, но и медиџинских услуг; возмещения вреда, причиненного смертью кормильца, увечьем или иным повреждением здоровья, связанным как с труАовой деятельностью, так и с Аругими обстоятельствами [9] . Соответственно, жизненные обстоятельства, с которыми была связана необходимость получения БЮП, выходияи за рамки предусмотренных Законом № 324-ФЗ случаев оказания БЮП.

Таким образом, практика применения Закона № 324-Ф3 показала, что одним из его основных недостатков явмяется необоснованно узкий перечень случаев оказания бесплатной правовой помощи гражданам. Необходимо отметить и достаточно узкий перечень субъектов, имеющих право на БЮП в рамках государственной системы. Так, к одной из категорий, имеющих право на бесплатную юридическую помощь, относятся малоимущие гражАане. ПоА Аанным термином в ст. 20 Закона № 324-Ф3 подразумеваются «граждане, среАнеАушевой дохоА семей которых ниже величины прожиточного минимума, установменного в субъекте Российской Федерации в соответствии с за-

42 Bulletin of the Volga Region Institute of Administration • 2019. Vol. 19. № 1 
конодательством Российской Федерации, кибо одиноко проживающие граждане, доходы которых ниже величины прожиточного минимума». Вместе с тем в стране проживает достаточно много граждан, средний доход которых несушественно превышает прожиточный минимум. Такие категории граждан фактически нужАаются в бесплатной юридической помощи, а юридически не имеют никаких прав не ее получение в рамках государственной системы. Это создает серьезные препятствия дмя многих фактически нуждающихся в оказании такой помощи, но не относящихся в соответствии с Законом № 324-Ф3 к указанному перечню граждан [9, с. 74] .

ОАним из вариантов разрешения указанных проблем, на наш взгляА, может стать региональное законотворчество. Субъектам РФ предоставлена прерогатива дополнять федеральное законодательство собственным перечнем субъектов, имеющих право на БЮП и случаев оказания такой помощи. В качестве примера подобного законотворчества можно привести Закон Саратовской области от 23 апреля 2012 г. № 63-3СО «Об оказании бесплатной юридической помощи в Саратовской области» [10]. По инищиативе Уполномоченного по правам человека в Саратовской области в 2018 г. в данный Закон внесены изменения, расширяющие перечень субъектов, имеющих право на БЮП.

Участники негосударственной системы бесплатной юридической помощи (юридические клиники и негосударственные центры бесплатной юридической помощи), в отличие от ранее рассмотренных субъектов государственной системы БЮП, не получают бюджетного финансирования своей деятельности. Их отличает также относительная самостоятельность в определении категорий граждан, которым они вправе оказывать бесплатную правовую помощь и случаев оказания такой помощи - Закон № 324-Ф3 не устанавливает здесь ограниченного перечня. Условия оказания бесплатной юридической помощи определяются каждым участником негосударственной системы БЮП самостоятельно, тем не менее они придержкиваются некоторых общих принщипов: потенциальными «клиентами» здесь обычно являются соџиально уязвимые категории граждан - малообеспеченные, пенсионеры, инвалиды, безработные, многодетные семьи.

Юридические кАиники, положительный опыт работы которых существовал еще в дореволюџионной России [11, с. 898-900], получили новое развитие в стране в 1990-е годы. Как правило, они создаются в качестве структурного подразделения вуза. Правовую помощь оказывают студенты, обучающиеся по юридическому профилю, под руководством преподавателей-кураторов [12] . Правовой основой их деятельности явмяется приказ Минобразования РФ от 30 сентября 1999 г. № 433 «О правовых консультаџиях («правовых клиниках») Амя насемения на базе вузов, осуществАяющих подготовку юридических кадров», Закон № 324-Ф3, некоторые иные акты. Аанная форма оказания БЮП получияа в последнее время достаточно широкое распространение, поскольку соответствующие образовательные стандарты предусматривают создание подобных структур в каждом вузе, ведущем подготовку спеџиалистов в 
правовой сфере. По данным АНО «Центр развития юридических клиник», в России сегодня действует около 270 юридических клиник [13]. Студенты, оказывающие правовую помощь в юридических клиниках, имеют уникальную возможность уже в ходе обучения получить опыт практической деятельности по своей будущей профессии. Работа студентов по оказанию БЮП осуществляется на добровольных началах и, соответственно, отличается высокой мотивацией обучающихся к получению практического опыта и волонтерской работе. Как показывает мониторинг деятельности юридических клиник, несмотря на несколько большие (в сравнении с иными участниками системы БЮП) сроки рассмотрения поступивших обращений, граждане в подавмяющем большинстве случаев остаются довольными качеством полученной правовой помощи.

Среди проблем организации и развития юридических клиник можно выделить прежде всего недостаточное финансирование их деятельности. Разрешение Аанного вопроса обычно целиком зависит от вузов, при которых созданы соответствующие структуры, а возможности образовательных учреждений в расходовании средств на оказание БЮП достаточно ограничены. Работа преподавателей-кураторов юридических клиник ведется чаще всего на общественных началах мибо за символическую плату. Существует и некоторая колмизия в действующем законодательстве относительно видов правовой помощи, которые вправе оказывать юридические клиники. Так, ч. 4 ст. 23 Закона № 324-Ф3 закрепляет, что они «могут оказывать бесплатную юридическую помощь в виде правового консультирования в устной и письменной форме, составления заявлений, жалоб, ходатайств и других документов правового характера». Таким образом, представительство интересов граждан в судебных и иных органах как вид правовой помощи данным актом не предусмотрен. В соответствии же со ст. 51 ГПК РФ представителем в суде может быть дееспособное киџо, уполномоченное на ведение дела соответствующим образом (за исключением миц, спеџиально указанных в ст. 51 ГПК). Руководствуясь Аанной нормой, стажеры юридических кАиник могут (поА руководством преподаватемей) осуществлять представительство интересов граждан в судебных органах, такой положительный опыт в ряде регионов имеется. Вместе с тем отметим, что подготовка к ведению дела в суде (и руководство данным процессом со стороны преподавателя) требует значительных временных и организационных затрат, осуществить которые в рамках работы юридических кАиник бывает Аостаточно сложно.

Еще одним участником негосударственной системы БЮП в соответствии с Законом № 324-ФЗ явмяются негосударственные центры беспиатной юридической помощи. Некоммерческие организации, адвокаты, адвокатские образования, адвокатские палаты субъектов РФ, нотариусы, нотариальные палаты могут создавать такие џентры в качестве юридических миџ - некоммерческих организаџий или структурных еАиниџ юридических миџ, Аибо без образования юридического миџа.

Виды бесплатной юридической помощи, категории граждан, имеющих право на ее получение, и перечень правовых вопросов, по которым такая

44 Bulletin of the Volga Region Institute of Administration • 2019. Vol. 19. № 1 
помощь оказывается, определяются негосударственными центрами бесплатной юридической помощи самостоятельно. При этом к категориям граждан, имеющих право на получение БЮП, прежде всего Аолжны относиться миџа с низкими Аоходами или находящиеся в труАной жизненной ситуации (ст. 24 Закона № 324-Ф3).

Регистрация и учет негосударственных центров бесплатной юридической помощи проводится Министерством юстиции РФ. К началу 2015 г., например, в стране зарегистрировано 138 таких центров [14], то есть создание негосударственных центров БЮП в России пока нельзя назвать массовым явмением. Те или иные виды беспматной правовой помощи продолжают сегоАня оказывать и различные общественные объединения (общественные организации, общественные фонды и др.), не зарегистрированные в качестве негосударственных центров бесплатной юридической помощи. Все подобные организации, наряду с негосударственными центрами БЮП, вынуждены самостоятельно находить источники финансирования своей деятельности, что явцяется одной из основных проблем в этой сфере. Закон № 324-ФЗ преАусматривает, что органы государственной власти и местного самоуправления могут осуществцять подАержку некоммерческих организаций, являющихся участниками негосударственной системы беспиатной юридической помощи. ОАнако ее объемы достаточно скромны. В качестве позитивных примеров оказания финансовой помощи негосударственным организациям, оказывающим БЮП, можно привести деятельность Фонда президентских грантов, осуществляющего подАержку, в том числе и негосударственных центров беспиатной юридической помощи.

Проведенный анализ некоторых особенностей развития системы бесплатной юридической помощи в России позволяет слелать следующее закАючение.

В последние годы, с принятием и реализацией Закона № 324-Ф3, система бесплатной юридической помощи в России переживает новый этап своего развития, связанный с ее упорядочением и более детальным правовым регулированием данной сферы общественных отношений. Получают свое развитие как традиционные Аля нашей страны, так и новые организационные формы оказания БЮП. Таким образом, возможность получения бесплатной юридической помощи дия широкого круга граждан, безусловно, увеличилась. Потребность в получении такой помощи также неуклонно растет, что вызывает необходимость повышенного внимания к этой проблеме государственных и муниципальных органов власти, юридического сообщества, учрежкений высшего образования. Необходимо проводить постоянный мониторинг Аоступности квалифицированной бесплатной юридической помощи Аля населения, качества ее оказания; повышать эффективность деятельности участников как государственной, так и негосударственной систем БЮП. Эти меры, на наш взгляА, будут способствовать развитию правовой культуры населения, более эффективной реализаџии и защите прав граждан, решению многих соџиальных проблем. 


\section{Библиографический список}

1. Росстат назвал число россиян, живущих за чертой бедности. URL: https://ura.news/ news/1052362631

2. Бедность в России: десятки миллионов за чертой. URL: https://www.gazeta.ru/business/2018/05/09/11745109.shtml?updated

3. О бесплатной юридической помощи в Российской Федерации: Федер. закон от 21 нояб. 2011 г. № 324-Ф3 ( в ред. от 28 нояб. 2015 г.) // С3 РФ. 2011 г. № 48. С. 6725.

4. Зеленский П.А. Проблемы эффективности организации государственной системы бесплатной юридической помощи // Конституционно-правовые проблемы эффективности публичной власти: теория и практика: сборник научных статей. Саратов, , 2018.

5. Чумакова O.B. Государственное юридическое бюро как участник системы бесплатной юридической помощи // Административное право и процесс. 2014. № 5.

6. О проведении эксперимента по созданию государственной системы оказания бесплатной юридической помощи малоимущим гражданам: постановление Правительства РФ от 22 авг. 2005 г. № 534 (утратило силу) // С3 РФ. 2005. № 35. Ст. 3615.

7. Пояснительная записка к проекту Закона Саратовской области «О внесении изменений в Закон Саратовской области «Об оказании бесплатной юридической помощи в Саратовской области»). URL: https://srd.ru/documents/pr_zaks/5-10464-pzp.pdf

8. Доклад Уполномоченного по правам человека в Чувашской Республике за 2014 г. Чебоксары, 2015.

9. Зеленский П.А. Правовое просвещение населения как фактор развития территории // Управление стратегическим развитием территорий: сборник научных трудов. Саратов, 2016.

10. Об оказании бесплатной юридической помощи в Саратовской области: Закон Саратовской области от 23 апр. 2012 г. № 63-3СО (в ред. от 26 июня 2018 г.) // С3 Сарат. обл. 2012. № 12.

11. Шугрина Е.С. Юридическая клиника в России: новое или хорошо забытое старое? // Актуальные проблемы российского права. 2013. № 7.

12. О правовых консультациях («правовых клиниках») для населения на базе вузов, осуществляющих подготовку юридических кадров: приказ Минобразования РФ от 30 сент. 1999 г. № 433 (в ред. от 1 марта 2004 г.) // Бюллетень Минобразования РФ. 1999. № 11.

13. Официальный сайт AHO «Центр развития юридических клиник». URL: http://codolc. com/clinics.

14. Доклад о деятельности Министерства юстиции Российской Федерации в сфере обеспечения граждан Российской Федерации бесплатной юридической помощью за 2014 г. // Российская газета. 2015. № 105, 19 мая. 